\title{
Improve the Role of Ibuprofen in the Biological Field: Short Review
}

\author{
Baraa Watheq, Alaa Mohammed, Mohammed H. Al-Mashhadani*, Emad Yousif \\ Department of Chemistry, College of Science, Al-Nahrain University, Baghdad, Iraq
}

*Corresponding Author: Mohammed H. Al-Mashhadani, Department of Chemistry, College of Science, Al-Nahrain University, Baghdad, Iraq

\begin{abstract}
Ibuprofen is an anti-inflammatory medication (NSAID) and it is also a non-steroidal, which might be providing relief from symptoms of inflammation and pain. However, Ibuprofen can cause risks such as stomach pain, heartburn, nausea, vomiting, gas, constipation and diarrhea. In order to decrease the side effect and enhance the role of Ibuprofen, the researcher improves different methods such as metal-Ibuprofen complexes synthesized and developed Ibuprofen-delivery systems.
\end{abstract}

Keywords: Ibuprofen, NSAID, Drug-delivery system.

\section{INTRODUCTION}

\subsection{History of Ibuprofen}

Chemically Ibuprofen is (2RS)-1[4-(2-methyl propyl) phenyl] propionic acid (figure 1) [1]. In 1961 Adams and Nicholson filed a patent for the Ibuprofen as analogue of aspirin that might be suitable for long-term use for rheumatoid arthritis [2]. The first clinical trials of Ibuprofen were performed by Dr Tom Chalmers in six patients with rheumatoid arthritis in 1966. From the results which have been reported, Ibuprofen produced enhancement in pressure tolerance (a measure of joint tenderness) with fewer marked enhancement in joint size [3]. It is non-steroidal anti-inflammatory drug (NSAID), which is antipyretic, analgesic which is used in mild to fever [4].

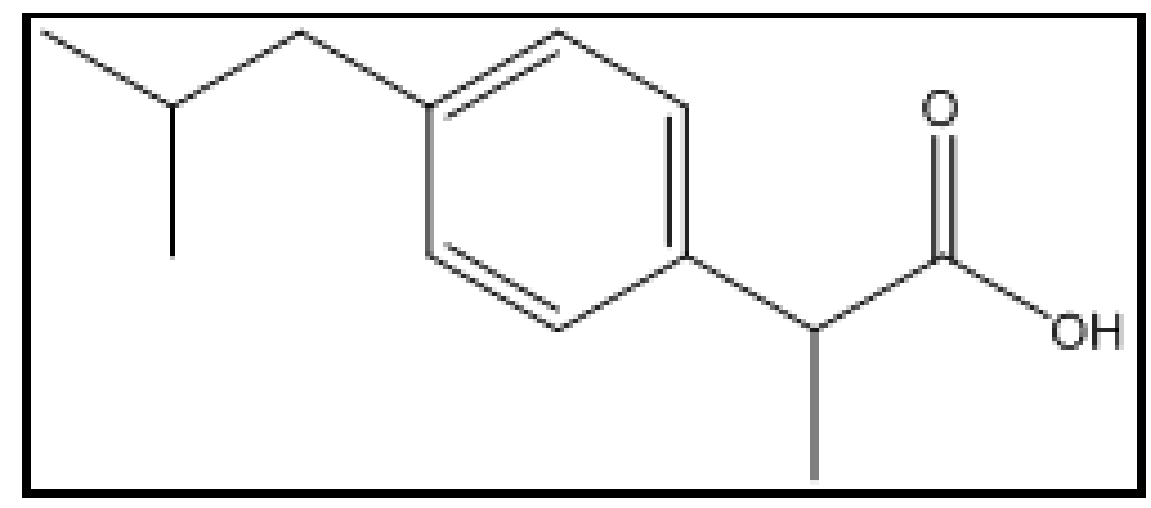

Figure1. Structure of Ibuprofen

\section{EXPERIMENTAL WORK REVIEW}

\subsection{Synthesis of Ibuprofen}

Ibuprofen (5) has been synthesized by reducing compound (1) utilizing sodium borohydride $(0.30 \mathrm{~g})$ in methanol as a solvent giving compound (2) 1-(4-isobutylphenyl)ethan-1-ol (2) as shown in Figure 2. It was used separatory funnel to shake compound (2) with $\mathrm{HCl}$ to give 1-(1-chloroethyl)-4isobutylbenzene (3). After that the last compound was converted to compound (4) Grignard reagent using turning magnesium in dry THF. Then 1,2-dibromoethane was added and about one litter of $\mathrm{CO}_{2}$ was bubbled inside the reaction mixture. The reaction was worked up by extraction and the solvent was evaporated by rotary evaporator to give pure Ibuprofen (5) see Figure 2 [5]. 


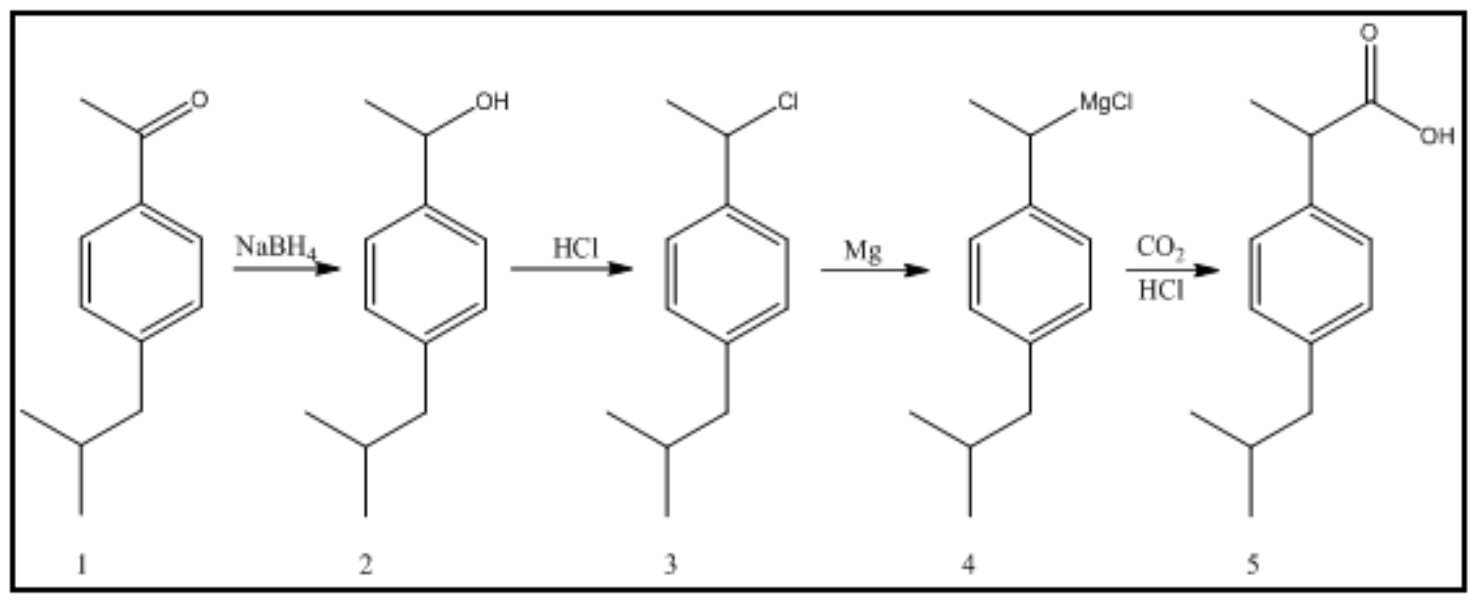

Figure2. Synthesis of Ibuprofen [5]

\subsection{Characterization of Ibuprofen}

Ibuprofen has been characterized by Fourier transform infrared (FTIR) spectroscopy (Figure 3) [6]. The $\mathrm{O}-\mathrm{H}$ stretching noticed in the $3600-3300 \mathrm{~cm}^{-1}$. The $v(\mathrm{C}=\mathrm{O})$ of the carboxylic acid group showed at $1719 \mathrm{~cm}^{-1}$. Several peaks noticed at $1506 \mathrm{~cm}^{-1}$ (Ring mode), 1461-1419 $\mathrm{cm}^{-1}$ (asymmetry $\mathrm{CH}_{3}$ ), 1379$1329 \mathrm{~cm}^{-1}$ (symmetry $\mathrm{CH}_{3}$ isopropyl), $1266 \mathrm{~cm}^{-1}$ (phenyl, p-substituted), $1183 \mathrm{~cm}^{-1}$ (CH isopropyl) [7].

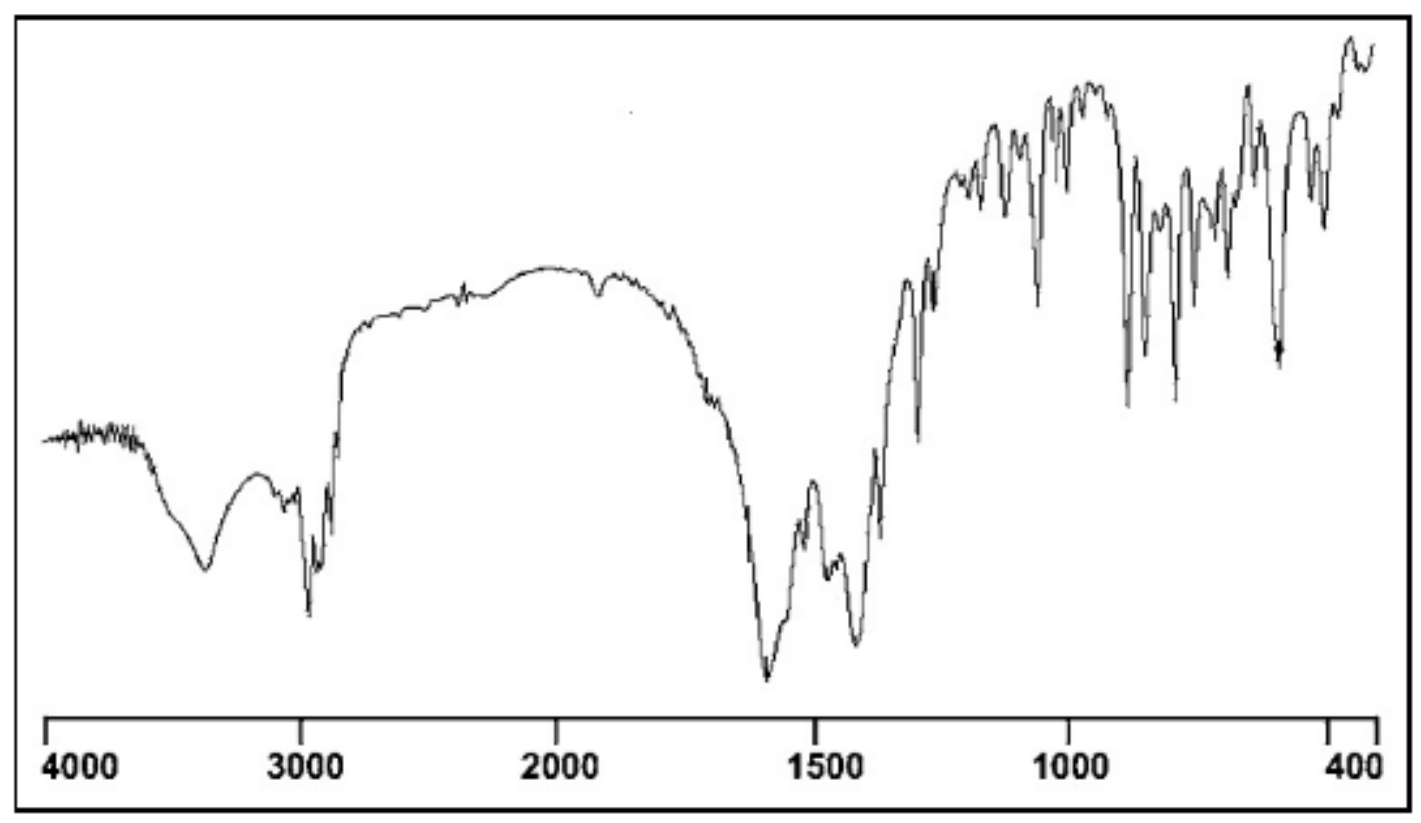

Figure3. FTIR spectrum of Ibuprofen [6]

According to nuclear magnetic resonance ( $\left.{ }^{1} \mathrm{H}-\mathrm{NMR}\right)$ spectroscopy, Ibuprofen characterized and reveals several chemical signals (figure 4) [8]. ${ }^{1} \mathrm{H}-\mathrm{NMR}$ spectrum show proton resonance at $3.72(\mathrm{q}, 1 \mathrm{H}, \mathrm{H}-2)$, 1.5 (d, 3H, H-3), 7.23 (d, 2H, H-5, 5'), 7.11 (d, 2H, H-6, 6'), 2.46 (d, 2H, H-8), 1.85 (m, 1H, H-9), 0.91 (d, 6H, H-10,10'); [9].

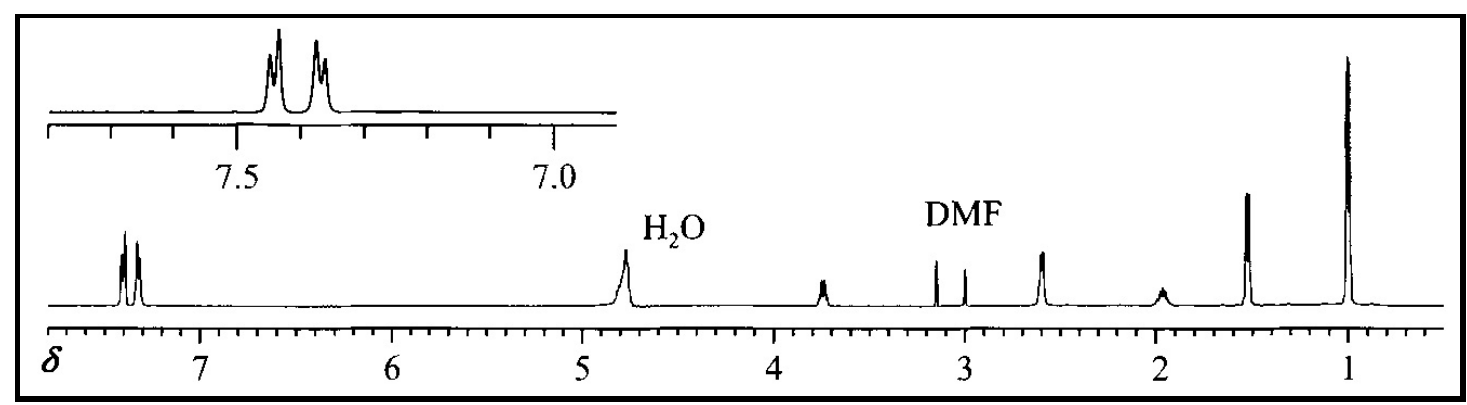

Figure4. ${ }^{1} H-N M R$ spectrum of Ibuprofen [8] 
It is worth mentioning that Ibuprofen characterized by scanning electron microscopy. Figure 5 show the crystal morphology of Ibuprofen [10].

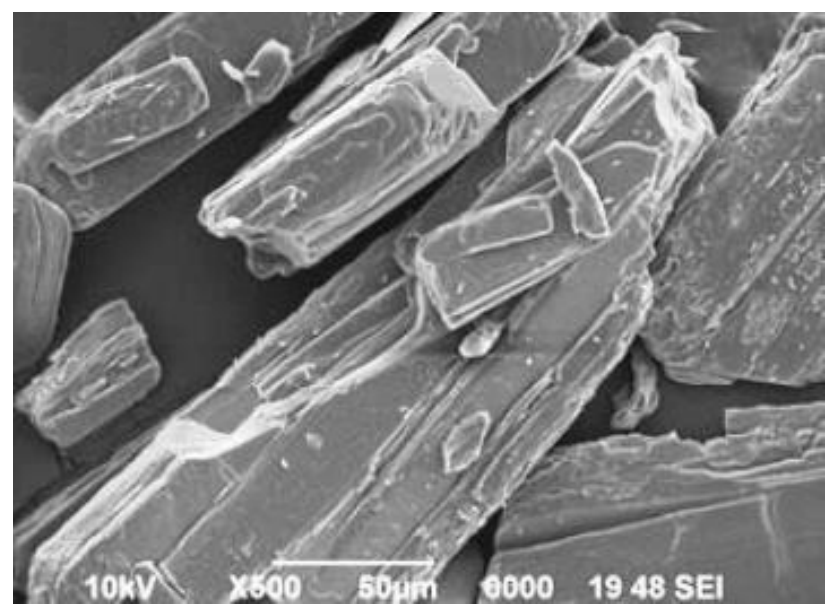

Figure5. SEM image of Ibuprofen [10]

\subsection{Side Effects of Ibuprofen}

Like any drug [11], Ibuprofen can cause risks, such common side effects are [12]:

- stomach pain

- heartburn

- nausea

- vomiting

- gas

- constipation

- diarrhea

\section{Metal-Ibuprofen COMPleXes USES}

Recently, Diphenyltin-, dibutyltin- and tributyltin-Ibuprofen complexes have been synthesized and characterized. Docking study carried out of these complexes and performed the capability of ligand (Ibuprofen) to cooperate within the active site of cyclooxygenases, which significant enzymes of the inflammatory process. Pharmaceutically, might be provide relief from symptoms of inflammation and pain [13]. In another study, Three complexes of $\mathrm{Zr}(\mathrm{IV})-, \mathrm{Ce}(\mathrm{III})-$ and $\mathrm{Th}(\mathrm{IV})-\mathrm{Ibuprofen}$ were synthesized and performed their activity against Escherichia coli, Pseudomonas aeruginosa, Bacillus subtilis and Bacillus cereus, Aspergillus niger and Aspergillus flavus organisms [14]. While MIbuprofen complexes ( $\mathrm{M}=\mathrm{Na}^{+}, \mathrm{Ag}^{+}, \mathrm{Ca}^{2+}, \mathrm{Mg}^{2+}, \mathrm{Cu}^{2+}, \mathrm{Zn}^{2+}$ and $\left.\mathrm{Hg}^{2+}\right)$ exhibited antibacterial activity against the Gram-positive bacteria (Staphylococcus aureus and Listeria monocytogenes) (Figure 6) [15,16].

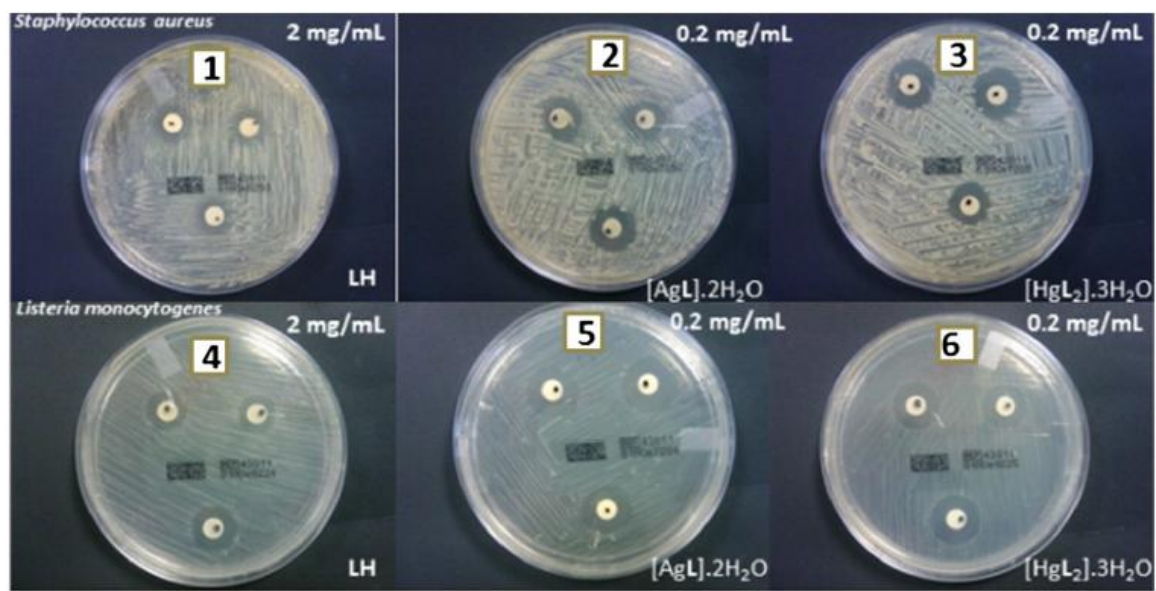

Figure6. Antibacterial, Ag-Ibuprofen (plots 2 and 5) and Hg-Ibuprofen (plots 3 and 6) complexes [15] 
In the same field of antibacterial and antifungal, M-Ibuprofen complexes ( $\mathrm{M}=\mathrm{Cu}$ (II), $\mathrm{Fe}$ (II), $\mathrm{Mn}$ (II) and $\mathrm{Co}(\mathrm{II})$ ) proved their activity versus Escherichia Coli (Gram -ve), Bacillus subtilis (Gram +ve) and antifungal (tricoderma and penicillium activities) [17]. On other hand, Ni(II)-, Mn(II)- and Pd(II)Ibuprofen complexes potential evaluated against leishmanicidal [18].

\section{IBUPROFEN-DELIVERY SYSTEMS}

According to adsorption phenomena, $\mathrm{Cu}(\mathrm{II})$-Ibuprofen complex has been synthesized and immobilized by adsorption on magnesium-aluminum dual hydroxides $\left(\mathrm{Mg}_{3} \mathrm{Al}-\mathrm{LDH}\right)$, in order to simulate the adsorption of the $\mathrm{Cu}(\mathrm{II})$-Ibuprofen complex on an antacid drug transporter may also be an effective substitute to decrease gastric irritation [19]. Furthermore, polymeric Ibuprofen prodrug of was synthesised by chemo-enzymatic procedure with molecular weight reached $2.126 \times 10^{4}$ (figure 7). In vitro studies, polymeric prodrug released at $\mathrm{pH} 7.4$ buffered solution at $37^{\circ} \mathrm{C}$ and evaluated by HPLC, which used for the qualitative analysis of the released product [20].

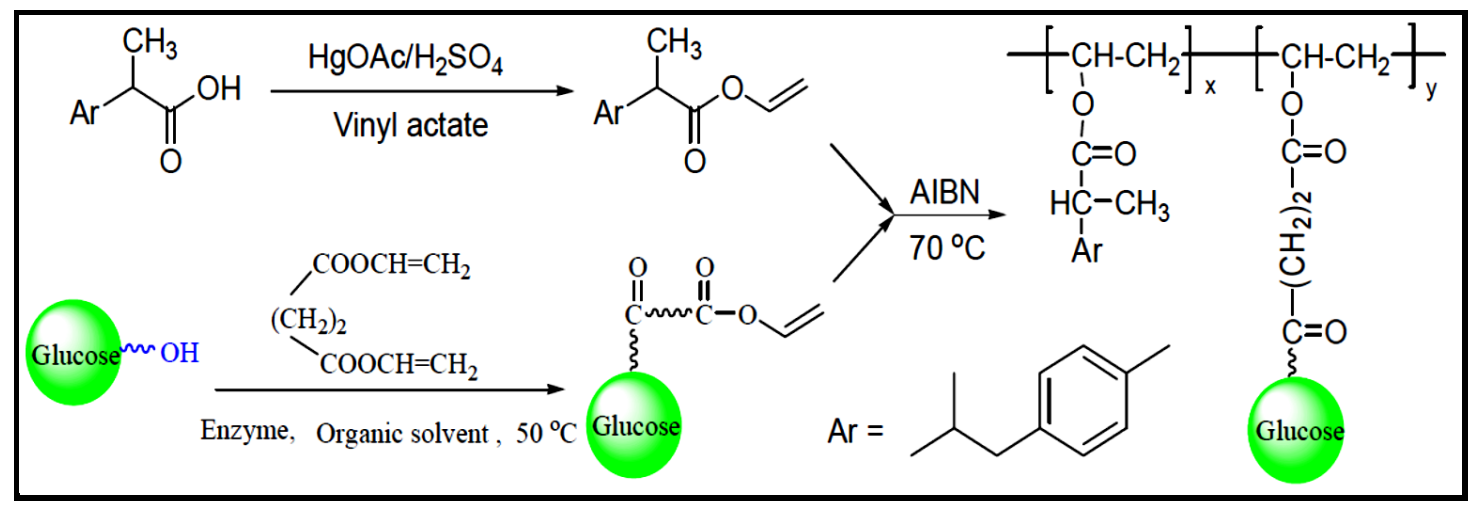

Figure7. Structure of polymeric prodrug of Ibuprofen

In recent study, two biocompatible Zinc-MOF-74 and UTSA-74 synthesized for ibuprofen delivery (Figure 8) in presence of phosphate buffer saline (PBS) solution [21]. In a previous study, MOF-74 and UTSA-74 have been prepared [22,23]. Zn MOF-74 was the higher biocompatible MOF for medication transport compare to UTSA-74 according to HPLC measuring.

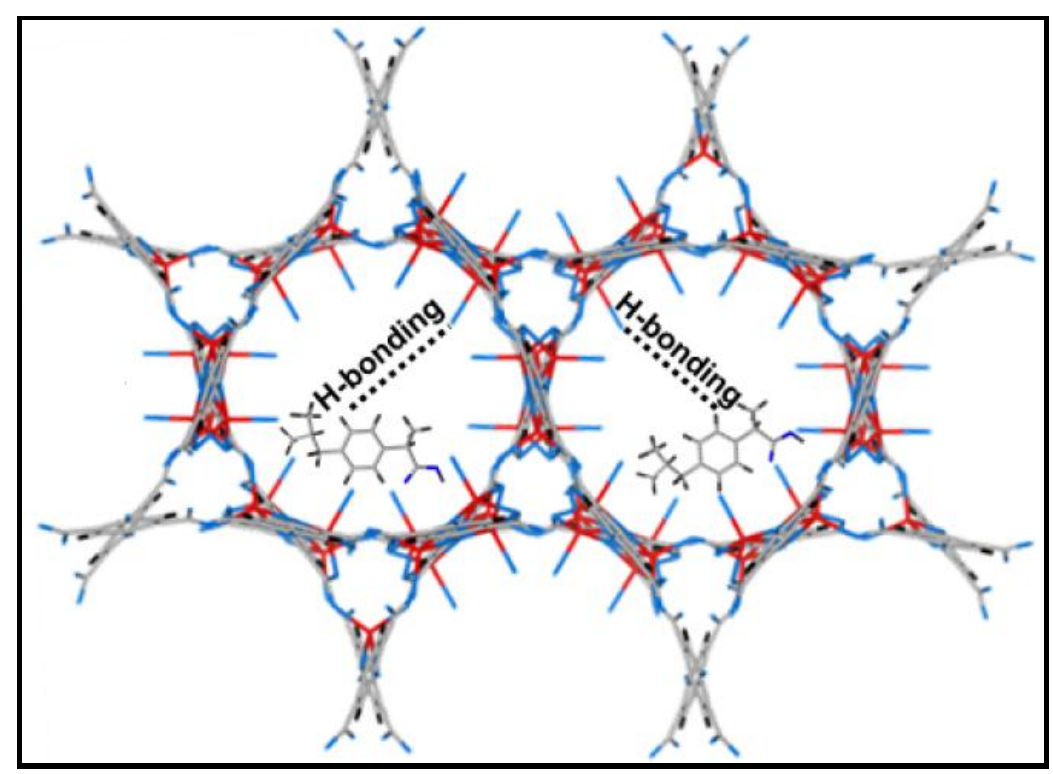

Figure8. Drug loaded MOF

Another drug-delivery system for Ibuprofen was Ibuprofen-phosphathidylcholine association (IPA) which induced the medication amorphous nature. That leads to enhance the Ibuprofen solubility in $\mathrm{pH}$ 7.2 of phosphate buffer medium [24]. Polydopamine (PDA) coverings functionalized on titanium dioxide nanotube layers (TNTs) were effectively synthesized. TNTs-PDA loaded IBU was applied on MC3T3 cell line. It was demonstrated that the prolonged medication release and Ibuprofen loading were significantly enhanced by the dopamine-modification TNTs. The medication loading improved by the interaction between Ibuprofen and the existence multifunctional groups [25]. 


\section{CONCLUSION}

Improving methods were enhanced the role of Ibuprofen in biological field. Where used as relief from symptoms of inflammation, pain, antibacterial and antifungal

\section{REFERENCES}

[1] Bushra R., Aslam N., (2010). An Overview of Clinical Pharmacology of Ibuprofen. Oman Medical Journal 2010;25: 155-161.

[2] Connelly D., A brief history of Ibuprofen. The Pharmaceutical Journal 2017.

[3] Rainsford K. D., History and Development of Ibuprofen. Ibuprofen 2015 1-21.

[4] Jasim H. H., Abed N. K. (2015). Determination of Ibuprpfen in Aqueaus Solutions and Pharmacetical Preparations by UV-VIS Spectrophotometric. Journal of Al-Nahrain University-Science 2015;18:1-9.

[5] Kjonaas R. A., Williams P. E., Counce D. A., Crawley L. R., Synthesis of Ibuprofen in the Introductory Organic Laboratory. Journal of Chemical Education 2011;88:825-828.

[6] Qandil A. M., Obaidat A. A., Ali M. A. M., Al-Taani B. M., Tashtoush B. M., Al-Jbour N. D., Badwan A. A., (2009). Investigation of the Interactions in Complexes of Low Molecular Weight Chitosan with Ibuprofen. Journal of Solution Chemistry 2009;38:695-712.

[7] Etcheverry S., Barrio D., Cortizo A., Williams P. A, Three new vanadyl(IV) complexes with non-steroidal anti-inflammatory drugs (Ibuprofen, Naproxen and Tolmetin). Bioactivity on osteoblast-like cells in culture. Journal of Inorganic Biochemistry 2002;88:94-100.

[8] Li C.-G., Liu M.-L., Ye C.-H., 1H NMR study of low-affinity binding of ibuprofen to human serum albumin at different pH. Applied Magnetic Resonance 2000;19:179-186.

[9] Kumari R., Banerjee S., Roy P., Nath M., Organotin(IV) complexes of NSAID, ibuprofen, X-ray structure of $\mathrm{Ph}_{3} \mathrm{Sn}(\mathrm{IBF})$, binding and cleavage interaction with DNA and in vitro cytotoxic studies of several organotin complexes of drugs. Applied Organometallic Chemistry 2019; 34(1).

[10] Acharya M., Mishra S., N. Sahoo R., Mallick S., Infrared spectroscopy for analysis of co-processed ibuprofen and magnesium trisilicate at milling and freeze drying. Acta Chimica Slovenica, 2017;45-54.

[11] Mousa O. G., Yousif E., Al-Mashhadani M. H., An Overview of Carvedilol Side Effects and it's Importance in Medicine and Industry. International Journal of Advanced Research in Chemical Science 2020;7:36-41.

[12] Carter A., Ibuprofen (Advil) Side Effects: What You Need to Know, University of Illinois, healthline, 2019.

[13] Romero-Chávez, M. M., Pineda-Urbina, K., Pérez, D. J., Obledo-Benicio, F., Flores-Parra, A., GómezSandoval, Z., \& Ramos-Organillo, Á. (2018). Organotin(IV) compounds derived from ibuprofen and cinnamic acids, an alternative into design of anti-inflammatory by the cyclooxygenases (COX-1 and COX2) pathway. Journal of Organometallic Chemistry 2018;862:58-70.

[14] Refat M. S., Mohamed G. G., El-Sayed M. Y., Killa H. M. A., Fetooh H., Al-Omar, M. A., Naglah A. M., Preparation, Spectroscopic, Theoretical Thermodynamic and Antimicrobial Discussions of $\mathrm{Zr}(\mathrm{IV}), \mathrm{Ce}(\mathrm{III})$ and $\mathrm{Th}(\mathrm{IV})$ Ibuprofen Drug Complexes. Journal of Computational and Theoretical Nanoscience 2016;13:5269-5276.

[15] Núñez C., Fernández-Lodeiro A., Fernández-Lodeiro J., Carballo J., Capelo J. L., Lodeiro C., Synthesis, spectroscopic studies and in vitro antibacterial activity of Ibuprofen and its derived metal complexes. Inorganic Chemistry Communications, 2014;45:61-65.

[16] Jabali B., Abu Ali H., New zinc(II) complexes of the Non-steroidal Anti-Inflammatory Drug (indomethacin) and various nitrogen donor ligands. Synthesis, characterization and biological activity. Polyhedron 2016;117:249-258.

[17] Ligational, Spectroscopic (Infrared and Electronic) and Thermal Studies on the $\mathrm{Mn}$ (II), $\mathrm{Co}$ (II), $\mathrm{Fe}$ (II) and $\mathrm{Cu}$ (II) Complexes with Analgesic Drugs. Canadian Chemical Transactions 2014;24-35.

[18] Cunha, L. C., Lage, D. P., Ferreira, L. S., Saboia-Vahia, L., Coelho, E. A. F., Belo, V. S., ... da Silva, E. S., Leishmanicidal activity of ibuprofen and its complexes with $\mathrm{Ni}(\mathrm{II}), \mathrm{Mn}(\mathrm{II})$ and $\mathrm{Pd}(\mathrm{II})$. Inorganic Chemistry Communications 2020;113:107756.

[19] Gordijo C. R., Barbosa C. A. S., Da Costa Ferreira A. M., Constantino V. R. L., Oliveira Silva D., Immobilization of Ibuprofen and Copper-Ibuprofen Drugs on Layered Double Hydroxides. Journal of Pharmaceutical Sciences 2005;94: 1135-1148.

[20] Wu C.-Y., Quan J., Xie J.-G., Zhu L.-M., Branford-White C. J., Preparation and Release Dynamic of Ibuprofen Polymeric Prodrug with Glucose Pendant. 4th International Conference on Bioinformatics and Biomedical Engineering 2010. 
[21] Lawson, S., Newport, K., Schueddig, K., Rownaghi, A. A., Rezaei, F., Optimizing ibuprofen concentration for rapid pharmacokinetics on biocompatible zinc-based MOF-74 and UTSA-74. Materials Science and Engineering: C 2020 117, 111336.

[22] T. Grant Glover, G.W. Peterson, B.J. Schindler, D. Britt, O. Yaghi, MOF-74 building unit has a direct impact on toxic gas adsorption, Chem Eng Sci. 2011;66:163-170.

[23] F. Luo, C. Yan, L. Dang, R. Krishna, W. Zhou, H. Wu, X. Dong, Y. Han, T.L. Hu, M. O’Keeffe, L. Wang, M. Luo, R.B. Lin, B. Chen, UTSA-74: A MOF-74 isomer with two accessible binding sites per metal center for highly selective gas separation, J Am Chem Soc. 2016;138:5678-5684.

[24] Amirinejad M., Davoodi J., Abbaspour M. R., Akhgari A., Hadizadeh F., Badiee A., Preparation, characterization and improved release profile of ibuprofen-phospholipid association. Journal of Drug Delivery Science and Technology, 2020;60:101951.

[25] Li L., Xie C., Xiao X., Polydopamine modified TiO2 nanotube arrays as a local drug delivery system for ibuprofen. Journal of Drug Delivery Science and Technology 2020;56:101537.

Citation: Mohammed H. Al-Mashhadani, et.al, "Improve the Role of Ibuprofen in the Biological Field: Short Review”, International Journal of Advanced Research in Chemical Science, 7(6), pp. 1-6. DOI: https:// doi.org/10.20431/2349-0403.0706001

Copyright: (c) 2020 Authors, This is an open-access article distributed under the terms of the Creative Commons Attribution License, which permits unrestricted use, distribution, and reproduction in any medium, provided the original author and source are credited. 